\title{
Analysis on the Current Situation and Countermeasures of Elevator Safety in China
}

\author{
Qi Lan ${ }^{1, \text { a) }}$, Dandan Zhang ${ }^{2, \text { b) }}$, Yalei Li ${ }^{1, \text { c) }}$ \\ ${ }^{1}$ School of Management, China University of Mining and Technology (Beijing), BeiJing, P.R.China \\ ${ }^{2}$ China Special Equipment Inspection and Research Institute, Beijing, China \\ a) marklan@qq.com \\ b) 104696044@qq.com \\ c)1037666218@qq.com
}

\begin{abstract}
There is in general no big fluctuation in elevator safety in China, but there are still underlying problems in elevator safety guarantee, such as enterprises' excessive pursuit of profit, inefficient maintenance and weak social safety consciousness. Considering those problems, this paper suggested getting enterprises to further fulfill their main body responsibility, further improving the safety supervision pattern and further enhancing safety publicity education in the hope of providing reference for elevator safety guarantee in China.
\end{abstract}

Keywords: elevator safety, AQSIQ, management

Elevator as residential buildings, office buildings and other buildings have a vertical transportation, like other traffic tools, become an indispensable part of our daily life, the elevator safety becomes more and more important[1].Like many other transportation tools, elevators have become an essential part of our daily life, hence making the safety of elevators an increasingly important issue. Elevator safety accidents occurred frequently in July, 2015: an elevator engulfed a passenger in Jingzhou, Hubei province of China on July 26; an elevator killed a passenger with her head getting stuck in Hangzhou on July $30 \ldots .4$ accidents occurred one after another in a week, killing 3 people and wounding 1 person, shocking the public a lot. However, after being startled, heartbroken and grieved, we should take a more objective look at the current safety situation, make an analysis on the causes behind the accidents with a cool head, and take effective preventive measures to avoid similar tragedies and stay right beside safety all the time.

\section{THE OVERALL SITUATION OF ELEVATOR SAFETY}

Since the birth of the world's first safe elevator in the United States in 1852[2], elevator safety technology has advanced rapidly and elevator performance has been greatly improved, which raised the safety level of 
elevators. China is the largest producer and user of elevators in the world. Elevator has become an important means of transportation in production and living, with over 200 million people taking the elevator every day, and it makes it quite convenient for daily trips and the transportation of goods. But as a large and complicated electromechanical product, elevator is quite dangerous, brings potential hazards and directly endangers people’s lives and property.

At the same time, the Chinese community especially government regulators made great efforts to strengthen elevator safety governance. In 2015, the General Administration of Quality Supervision, Inspection and Quarantine of the People's Republic of China (AQSIQ) launched the elevator safety supervision and control battle. On the basis of self-examination and self-correction, through supervision and inspection, 107,000 elevators with hidden troubles were found, more than 1,900 elevators were stopped and 101,000 elevators were rectified, of which 13 thousand elevators without property management, without maintenance and without maintenance fund, namely "three-without", were renovated and 13,000 old elevators were transformed[3].

In 2016, from 15 cities in the end of 2015, elevator emergency service platforms quickly expanded to 92 cities, of which 12 cities could upload data to the AQSIQ Elevator Failure Data Statistical Analysis Platform and 19 provinces opened emergency special number. The average time for elevator rescuers to arrive at the scene and implement rescue was significantly reduced. All parts of the country actively acted and innovated means which had a lot of highlights. For example, Beijing opened the emergency channel for residential special maintenance funds and solved the aging problems of residential elevators in mega-cities. Guizhou used big data cloud platforms to promote the construction of elevator safety supervision system and creatively launched the activity of "Elevator Safety Management Demonstration Area" in Liupanshui City. Jiangsu, Shaanxi, Guizhou and other provinces constructed elevator emergency disposal platforms. Jiangsu set up a provincial elevator failure data processing and analysis center to achieve the connectivity with the AQSIQ platform data[4].

AQSIQ also stepped up the work of elevator legislation. "The Regulations on Elevator Safety" was included in the legislative work plan of the State Council in 2016. In consideration of the harsh working conditions and accidents of domestic elevators, the safety technical norms such as "Elevator Type Test Rules" were promulgated and more stringent technical requirements were proposed. AQSIQ organized and launched the "Self-Declaration for Elevator Enterprises' Maintenance Standards and Public Commitment to Service Quality" to guide enterprises to further improve the quality of daily maintenance of the elevators.

By the end of 2015, there had been 4.25 million elevators in use in China, and an annual growth rate of $20 \%$ or so was maintained. Compared with 2002, 2015 saw an increase of over 10 times in elevator number, with China ranking first worldwide in terms of elevator population, annual production and annual growth[5]. In the meantime, with the joint efforts of all social sectors concerned, including manufacturing enterprises, trade organizations and regulators, the accident rate of every ten thousand elevators decreased by 11 times gradually from 1.56 to 0.14 , the number of fatality in every ten thousand elevators decreased gradually from 1.33 to 0.10 , with the death rate going down by 13 times, and the level of elevator safety was already basically the same as that in developed countries [6]. The elevator safety situation in recent years is shown below. 
TABLE 1. 2010-2015 China Elevator Safety Accidents

\begin{tabular}{cccccc}
\hline & $\begin{array}{c}\text { Number of } \\
\text { Elevators } \\
\mathbf{( 1 0 , 0 0 0 )}\end{array}$ & $\begin{array}{c}\text { Number of } \\
\text { Fatalities } \\
\text { (Person) }\end{array}$ & $\begin{array}{c}\text { Number of } \\
\text { Accidents }\end{array}$ & $\begin{array}{c}\text { Mortality Rate Per } \\
\mathbf{1 0 , 0 0 0} \text { Equipment }\end{array}$ & $\begin{array}{c}\text { Accident Rate Per } \\
\mathbf{1 0 , 0 0 0} \text { Equipment }\end{array}$ \\
\hline 2010 & 162.85 & 44 & 44 & 0.27 & 0.27 \\
\hline 2011 & 201.06 & 42 & 64 & 0.21 & 0.32 \\
\hline 2012 & 245.33 & 34 & 42 & 0.14 & 0.17 \\
\hline 2013 & 300.93 & 57 & 70 & 0.19 & 0.23 \\
\hline 2014 & 359.85 & 48 & 95 & 0.13 & 0.26 \\
\hline 2015 & 425.96 & 46 & 58 & 0.11 & 0.14 \\
\hline
\end{tabular}

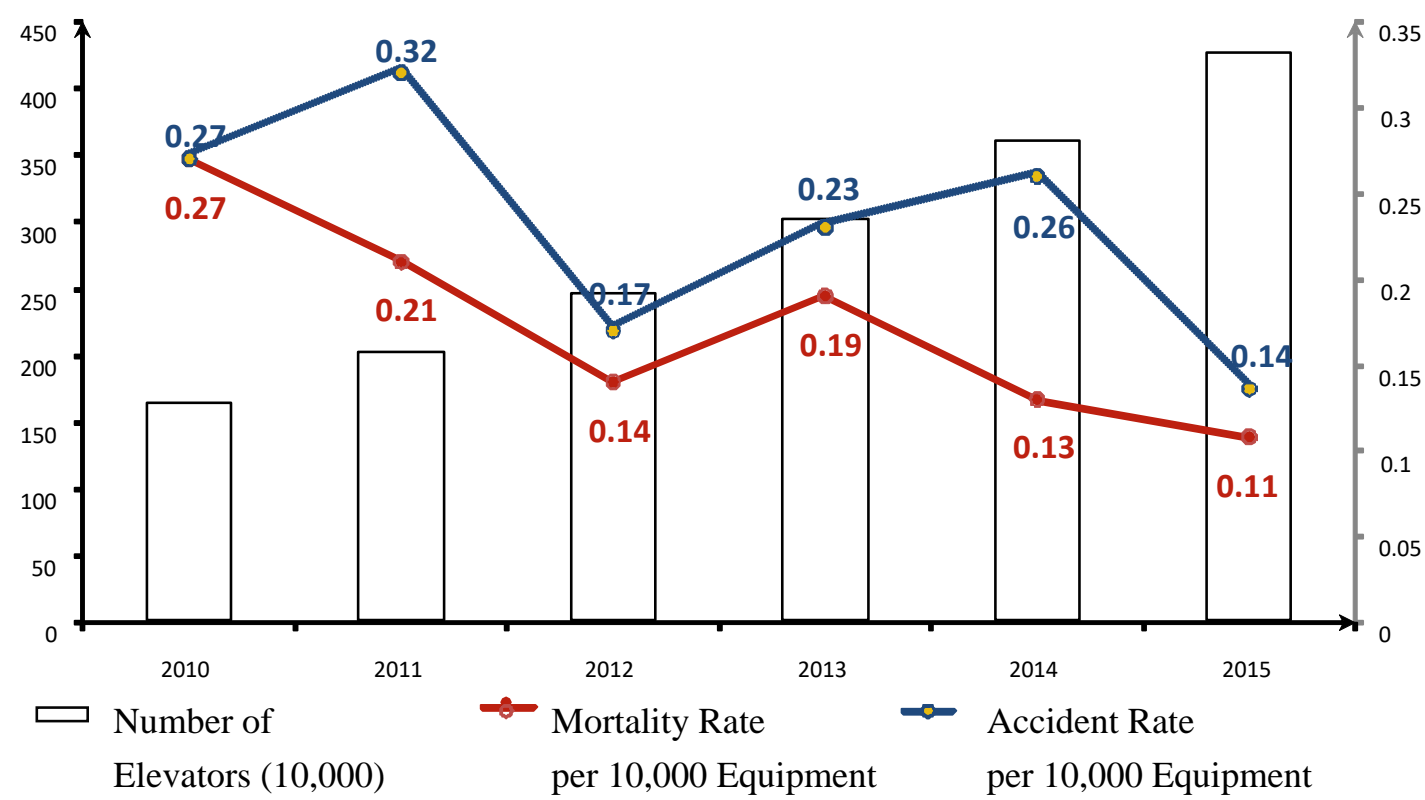

FIGURE 1. 2010-2015 China Elevator Safety Accident Trend

The overall safety level of elevators in China keeps improving in recent years. Compared with the death rate per 10,000 vehicles of traffic accidents, hitting 3.6 in 2009 [7], the death rate per 10,000 elevators is relatively low. But the security situation of elevators cannot be simply contrasted like this. Firstly, though the death rate and accident rate of elevators are not high, elevators see high failure rate. Take Shenzhen city as an example, there were 1,561 effective complaints about special equipment in 2015. Elevators alone contributed 1,544 effective complaints and reasons included that people got trapped in elevators, there was abnormal sound, elevators fell down and etc. Based on a total number of 132,000 elevators in Shenzhen, the failure rate per 10,000 elevators reached 117.0. Take Hangzhou city as an example, the number of elevators used in the city reached 82,000 in end 2015. There were 6,878 emergency rescues concerning elevators, representing a failure rate per 10,000 elevators of 838.8. Factors like different actual situations and statistics requirements might explain the large gap between the failure rates of elevators in Shenzhen and Hangzhou, but it still suggests comparatively high failure rate of elevators. Secondly, though the number of casualties resulted from elevator accidents is not large, it brings huge social risks. For instance, 1 person got killed in the elevator accident in 
Jingzhou city, Hubei province, 18 people lost their lives in the crane collapse in Dongguan city, Guangdong province and 33 people died in the coal mine explosion in Yongchuan city, Chongqing municipality, but 4,370 news reports, 16 news reports and 1,690 news reports about the three accidents were found respectively through Baidu's “news search". It suggests that the public opinion pays great attention to elevator accidents. Panic about taking the elevator even pervades the whole society. The security situation of elevators does not look good.

\section{THE PROBLEMS IN ELEVATOR SAFETY GUARANTEE}

Despite the little fluctuation in elevator safety, for every victim and his family, every accident is an irretrievable loss, so we must deeply analyze the reasons of these accidents. Leaving aside the pure technical factors in elevator design, manufacturing, use and maintenance, we can easily find that there are also some deeper problems restricting the promotion of elevator safety level.

The first is enterprises' excessive pursuit of profit. Virulent price competition and excess capacity exist in the elevator industry. Like all other industries, the elevator industry is susceptible to virulent competition since it has inevitably led to cost squeeze, replacement of materials with inferior ones, and reduction of some essential functions, making it difficult to guarantee the elevator quality. Since elevator users don't have an option, and a low price caters to the requirements of elevator purchasers like real estate developers, shopping malls and supermarkets, a "lemon market" similar to bad money driving out good has been formed. According to media reports, some elevator manufacturing enterprises price their products $25 \%$ lower than the like products, and for these enterprises, low price competition is an upper hand, but it is also a hidden peril [8].

The second is inefficient maintenance. According to a survey on elevator maintenance in 2012, maintenance and usage made up $60 \%$ of the factors contributing to elevator vulnerability [9]. Among the 95 elevator safety accidents occurring in 2014 , more than $76 \%$ were caused by the failure of safety components. Thus, the most effective means for avoiding failure is to strengthen maintenance. It is clearly required in China's Regulations on Safety Supervision of Special Equipment that "an elevator should be cleaned, lubricated, adjusted and inspected at least every 15 days”, but this is something inacceptable in practice. In addition, the third-party maintenance market is also in chaos. Some media made an in-depth investigation into elevator maintenance soon after the occurrence of a subway elevator accident in Beijing, learning that the manufacturer would charge 7000 Yuan for the annual maintenance of an elevator, while a third-party maintenance contractor would charge only 3000 Yuan or so” [10]. Therefore, many property management companies covetous of small gains usually chose these "low-price and low-quality" maintenance contractors. In addition, since residential elevators are owned by all the house owners, the owners committee often has difficulties in reaching a consensus on elevator management. Moreover, there are problems at the operational level, so it is hard to raise or use maintenance funds.

The third is weak social safety consciousness. Since elevator was introduced into China relatively late, the public does not have an adequate awareness of its fatalness, neither can safety propaganda receive due attention. Particularly in some public congregation places such as shopping mall, school, hospital, station and park there is lack of effective safety warning and safety management measure. Taking the accident in Jingzhou Hubei for example, the mall staff had seen the loosened inlet cover before the accident, but they did not take it seriously; in an interview after the accident, the mall staff admitted they had no idea of the emergency stop button, showing that the relevant staff never received safety training or education at work. Besides, the public often behaves badly when taking an elevator in everyday life. For instance, they fight noisily as if no one was nearby in the car, hit against the elevator door, press the control buttons for fun or handle goods by brute force. Some 
parents are neglectful in looking after their children, so that their children amuse themselves in the car. This is another cause for accident occurrence.

\section{MEASURES AND SUGGESTIONS ON STRENGTHENING ELEVATOR SAFETY GUARANTEE}

In the face of these problems, we should take a more effective measure to arouse all parties' enthusiasm to guarantee elevator safety and raise their consciousness of guaranteeing elevator safety.

First, get enterprises to further fulfill their main body responsibility. It is clearly demanded in Article 13 of the Special Equipment Safety Law that the manufacturers, distributors and users of special equipment, as well as the persons chiefly in charge, should take responsibility for the special equipment manufactured, distributed and used by them, and that these organizations should offer necessary safety education and skill training to special equipment safety managers, detection personnel and operating personnel in accordance with the national relevant stipulations[11]. Despite the clear legal provisions, why do the enterprises, as the first person responsible, not conduct safety management effectively? This is chiefly because of the mild punishment. In 2002, an elevator safety accident happened in America and shocked the whole nation. A 7-year-old girl had three of her fingers cut off by an elevator in a shopping mall. After the accident, the little girl's mother filed a suit against this shopping mall, and finally got a compensation of USD15 million [12]. Punitive compensation is adopted in the American justice system, while compensatory compensation is adopted in China's, so Chinese enterprises are rarely deterred. For example, in March this year, a 4-year-old girl was wounded in the arm on an escalator in a supermarket in Wuhan and the injury disability was identified as Level 10. However, in accordance with the judgment of court, the supermarket just borne $40 \%$ responsibility and compensated merely over 47 thousand Yuan; in June this year, a house owner in Fuzhou was killed by the residential elevator, and the property management company compensated only 750 thousand Yuan. The compensation consisted primarily of medical expense, disability compensation, death compensation, nursing expense, funeral expense, traveling expense, and a small amount of mental injury solatium, while punitive compensation was not included. Punitive compensation system has been included in China's Consumer Protection Act, Tort Liability Act and Food Safety Act. For example, it is stipulated in the Food Safety Act that the maximum compensation is worth ten times. Punitive compensation system should also be introduced into the special equipment field, since only a huge fine will be able to overpower the enterprises concerned, so that they would want to stay clear of all subjective mistakes.

Second, further improve the safety supervision pattern. At present, China can basically conduct effective proactive supervision on various special devices, including elevator, but interim and post-mortem supervision is not so satisfactory. Especially, the management over maintenance agencies should be strengthened to ensure that the daily safety guarantee of elevator would be implemented effectively. The manufacturers should take responsibility for their products in the whole lifecycle by bundling product sales and routine maintenance services together and meanwhile keep improving the product quality and safety management level by undertaking a clearer main legal responsibility. Besides, apart from administrative management over the maintenance agencies and personnel, a market mechanism should be set up in order to select the superior and eliminate the inferior. For example, the voluntary system of certification has come into play for the special equipment maintenance agencies in the petrochemical field. When being entrusted by a petrochemical enterprise to assess the qualification of a maintenance agency, a third-party institution usually makes use of a standard means to do this work to urge this petrochemical enterprise to choose a better maintenance agency, so as to 
clean the petrochemical maintenance market and promote the sound development of the petrochemical industry. An elevator liability insurance system should be introduced and perfected at full blast. Not only should the victim be given higher compensation after an accident, but the assurer ought to play a supervisory role, to promote all parties concerned to carry out safety responsibilities effectively to reduce the accident occurrence probability. UL, the most authoritative inspection and certification agency of America, was founded by some assurer, which has inspected and certified 9 billion products from the whole world, making outstanding contributions to safety business.

Third, further enhance safety publicity education. People are safety principals. So, only by strengthening safety publicity education continuously for producers, users and regulators can they have their safe consciousness and precaution consciousness enhanced, safety behavior standardized, and ideological awareness heightened for safety guarantee. Both government supervision department and enterprises should attach great importance to safety publicity education, increase funds input, enlarge the coverage and influence of publicity education, and make publicity education more targeted and effective. Highly visible and interesting warning signs and risk tips could be put up near the elevators in public gathering places to popularize safety knowledge more visually. Free brochures could be distributed to high risk groups in the areas where old people or children generally flock together, such as school, community, park and square, for safety education propaganda, to spread the legal knowledge of special equipment safety, as well as the relevant safety precautions. Free safety training could be conducted for elevator practitioners, penetrate safety consciousness into everybody's daily work and professionalism. Elevator safety propaganda films and animation-based public service advertisements could be made for publicizing elevator safety knowledge to the public via various traditional media, new media and we-media, to create a good atmosphere in which the whole society will unite in a concerted effort to jointly guarantee elevator safety.

\section{ACKNOWLEDGMENTS}

Corresponding author: Qi LAN, Ph.D. candidate, School of Management, China University of Mining and Technology (Beijing); research fields: public administration, governance, safety, quality, standardization. E-mail: marklan@qq.com. Dandan ZHANG, China Special Equipment Inspection and Research Institute; research fields: Special Equipment. E-mail: 104696044@qq.com. Yalei LI, School of Management, China University of Mining and Technology (Beijing); research fields: Management accounting. E-mail: 1037666218@qq.com.

\section{REFERENCES}

1. Wen Jian. Analysis and Solutions of Elevator Safety Hidden Trouble Factors [J]. Technology and Market, $2012(6)$.

2. Wang Jian. Elevator safety risk assessment system design and application [D]: [Master's Thesis]. Hangzhou: Zhejiang University of Technology, 2012.

3. Song Jihong. Insist on the Bottom Line of Safety, Comprehensively Deepen the Reform and Continue to Promote the Development of Special Equipment Safety and Energy Saving[R]. AQSIQ Website. 2016-02-24.

4. Jia Guodong. Unswervingly Continue to Promote the Development of Special Equipment Safety and Energy Saving[R]. AQSIQ Website. 2016-08-30. 
5. Tian Suqian. Elevator maintenance project risk management research - Suzhou Songze home maintenance project as an example [D]: [Master's Thesis].

6. He Shuangjuan.Passenger elevator safety risk assessment method research [D]: [Master's degree thesis].

7. Lu Jing. Strive to approach death rate per 10,000 vehicles in moderately developed countries [J].Transport Business China,2010(10)19.

8. Zhang Tengfei. Perspective of low-cost domestic-made elevator competition cycle: only ten thousand gross margin [J] Changjiang Daily, 2015 (8).

9. Wang Dong. Elevator management hidden dangers and countermeasures [J]. China's special equipment management research .2012,15 (6).

10. Chen Yuming. Xinhua Insight: How many potential safety hazards are there in elevators around us? [N].Xinhuanet,2011-7-11.

11. Standing Committee of the National People 's Congress. Special Equipment Safety Law of the People' s Republic of China.

12. Cunya X, Lejeune M. Statistical modeling and risk assessment [J]. Safety Science, 2003. 